\title{
FEMINIZAÇÃO DO PODER EM ESPAÇOS POPULARES: TRABALHO E RESISTÊNCIA SOCIAL*
}

\section{FEMINIZATION OF POWER IN POPULAR SPACES: WORK AND SOCIAL RESISTANCE}

Nilza Rogéria de Andrade Nunes

\begin{abstract}
Resumo: O presente trabalho tem por objetivo dar visibilidade à atuação das mulheres que são (re) conhecidas como referência em suas comunidades e/ou também nomeadas lideranças comunitárias. Seu protagonismo se deu a partir dos anos de 1990 e geopoliticamente se localizam em territórios segregados sócio espacialmente denominadas favelas ou comunidades no Rio de Janeiro. Essas mulheres representam um fenômeno que vem crescendo notadamente e que podemos classificar como "feminização do poder". Anunciando a construção cotidiana dessa mulher e seu lugar de destaque social e político, a agenda dessas personagens está comprometida com a transformação social e se conforma através de práticas e atitudes que preconizam o enfrentamento das múltiplas expressões de desigualdade e vulnerabilidade social que permeia os seus locais de moradia. Suas agendas transcendem o local acessando a cidade, o estado, o país, num movimento permanente em defesa da cidadania dos moradores de seus territórios e na afirmação de uma sociedade democrática e participativa. Por essas e outras razões é que podemos afirmar que a "feminização do poder" é, de fato, um movimento que emerge no cenário atual, compreendendo que há um protagonismo da mulher em condições de subalternidade.
\end{abstract}

Palavras Chaves: Mulher. Feminização do Poder. Favela.

Abstract: This study aims to give visibility to the performance of women who are (re) known as reference in their communities and / or also named community leaders. Their protagonism took place from the years of 1990 and geopolitically they are located in territories segregated partner spatially, denominated favelas or communities in Rio de Janeiro. These women represent a phenomenon that has grown remarkably and which we can classify as "feminisation of power". Announcing the daily construction of this woman and her place of social and political prominence, the agenda of these characters is committed to social transformation and is shaped

\footnotetext{
"Este trabalho é parte da pesquisa apresentada no 9 Congresso Latinoamericano de Ciência Política, organizado pela Associação Latino-americana de Ciência Política (ALACIP). Montevidéu, 26 a 28 de julho de 2017".

Doutorado em Serviço Social pela Pontifícia Universidade Católica do Rio de Janeiro (PUC-RJ) com estágio doutoral subsidiado pelo Programa de Doutorado Sanduíche no Exterior da CAPES na University of Dundee - Scotland - UK, Mestrado em Psicossociologia de Comunidades e Ecologia Social/Instituto de Psicologia e Graduação em Serviço Social ambos pela Universidade Federal do Rio de Janeiro (UFRJ). Professora do Departamento de Serviço Social da Pontifícia Universidade Católica do Rio de Janeiro (PUC-RJ) nos cursos de Graduação e Pós Graduação.
} 
by practices and attitudes that advocate coping with the multiple expressions of inequality and social vulnerability that pervades their places of housing. Their agendas transcend the place by accessing the city, the state, the country, in a permanent movement in defense of the citizenship of the inhabitants of their territories and in the affirmation of a democratic and participative society. For these and other reasons we can affirm that the "feminization of power" is, in fact, a movement that emerges in the current scenario, understanding that there is a protagonism of the woman in conditions of subalternity.

Keywords: Woman. Feminization of power. Favela. 


\section{INTRODUÇÃO}

Este estudo deseja refletir acerca do entendimento do que chamamos de "feminização do poder" (FONSECA; PAGNOCELLI; MAGALHÃES, 2008) - um processo sócio-político que vem ganhando conteúdos e representações próprias, principalmente a partir da ação pública de mulheres que, nas últimas três décadas, atuam com grande destaque e importância social em muitas das favelas do Rio de Janeiro.

As mulheres aqui referenciadas são as (re) conhecidas lideranças comunitárias as quais entendemos como um sujeito que é coletivo por natureza, é histórico e está diretamente associado ao contexto do amanhecer do século XXI no Brasil. Fazem gestão de territorialidades (redes) que se constroem como teias no interior de suas comunidades e cuja agenda política transcende o local, alcançando outros níveis de articulação para além da favela, da cidade e muitas vezes do país.

Ao assumir um papel de referência nos seus locais de moradia, seja através de um ativismo individual ou através da participação em organizações de base comunitária ${ }^{1}$, atuam em diferentes espaços de controle social e perseguem a garantia de direitos de cidadania para os moradores de suas favelas. A tomada de consciência e a criação de estratégias para enfrentamento dos problemas vivenciados nos seus territórios impulsionaram processos participativos que possibilitam a troca de saberes e experiências, e principalmente lutas e conquistas por políticas públicas.

Ela não é qualquer mulher e nem de qualquer lugar — ela é ícone da luta cotidiana de um segmento de mulheres da nossa população que vive subalternizada

\footnotetext{
${ }^{1}$ Essas organizações possuem características próprias por terem uma forte relação com a população onde se inserem. Normalmente elas são pequenas, já que atuam apenas em âmbito local. São organizações que, antes de tudo, conhecem muito bem o local onde atuam, seus problemas de fato e as pessoas que vivem lá. Na maioria das vezes não têm uma base conceitual ou metodológica forte, pois seu trabalho está muito mais fundamentado no conhecimento tácito e não no conhecimento teórico. Costumam ser generalistas, pois no local os problemas não são compartimentalizados e, sendo assim, acabam tendo que atuar em todas as pontas. Ao contrário de grandes organizações sociais, não se especializam em uma temática. Tendem a não ser formalizadas (com mudanças no atual cenário, já que, para se conseguir verbas de empresas e governo, é necessária a regularização). Em geral não possuem quase nenhum funcionário e alguns poucos voluntários (KELLOGG, 1999, p. 447 apud AVELAR, 2008). Normalmente o fundador da organização na prática é quem decide tudo, exercendo o papel de conselho e de presidente.
} 
por um modelo de desenvolvimento que delimita e cerceia o acesso e a garantia de direitos ${ }^{2}$.

A favela é o território de referência desse estudo, muitas vezes também denominada como comunidade por parte de seus moradores, do poder público e da sociedade em geral. Ela é parte da cidade, embora historicamente tenha sido recusada sua existência devido a sua imagem negativa, sinônimo de insegurança e violência.

Muito embora nossa compreensão de cidade se dê de forma integral, o recorte sócio espacial a que a mesma se refere especifica o que objetivamente pretendemos explorar: um lugar que exerce um papel essencial para a cidade no âmbito geográfico, econômico, social e político. Uma visão homogeneizada por parte da sociedade e um discurso voltado quase que exclusivamente para as ausências, corroboram com a imagem construída de não reconhecimento do morador de favela como um agente ativo e atuante, inserido no tempo e no espaço da cidade portanto, cidadão sujeito de direitos (FERNANDES, 2009).

A compreensão estereotipada que o imaginário social do conjunto da cidade reconhece como favela, sempre associada à reprodução do lugar subalterno e ao estigma que hoje se associa a cultura da violência. Há prevalência da representação do que a favela não tem e pouco se compreende sobre a solidariedade, as relações de vizinhança, a representação cultural e a força do povo, que de fato faz um movimento ainda que silencioso de permanente resistência à lógica da "exclusão".

No entanto, pretende-se aqui elucidarmos as potências que estes territórios nos apresentam. E para tal, são as mulheres as protagonistas aqui em cena. Para falar dessas mulheres faremos um breve percurso desse sujeito político que se constrói nos espaços populares - essas mulheres - nomeadas ativistas ou lideranças comunitárias. Seu território de pertença identitária, participação social e atuação política é atravessada por uma comunidade viva e real, repassada de tensões, de desejos, de ausências, de projetos de futuro, mas também de frustrações, de expectativas, de lutas que cansam e desanimam e de sonhos que se

\footnotetext{
${ }^{2}$ As reflexões aqui apresentadas decorrem de uma experiência profissional ao longo de 30 aos em favelas do Rio de Janeiro, de uma dissertação de Mestrado e uma Tese de Doutorado dialogando com a temática.
} 
concretizam e se consolidam. É da favela que virá a fala que representa um poder feminino que desponta de um movimento autônomo, individual e que se transforma em ações coletivas e articulações multifacetárias.

Nossa compreensão desse processo ainda nos traz o sentido de solidariedade que perpassa o ideário dessa mulher. $O$ fato de priorizarem questões coletivas sobre o seu tempo individual aponta para um sentido de reciprocidade, marcado pelo prazer e pela realização de conquistas em troca de um reconhecimento pelo seu valor como pessoa de referência no seu local de moradia, o que lhe confere um lugar de poder e de visibilidade.

Mais do que isso, falar de poder da mulher na favela é reconhecê-las a partir do crescente do protagonismo feminino no Brasil, que perpassa as diferentes classes sociais das diversas regiões do país na atualidade. Portanto, esse estudo busca evidenciar o que se pode chamar de "feminização do poder" num dado espaço de tempo e em uma dada conjuntura social.

\section{CAMINHOS PARA RESOLVER A VIDA}

Vivemos no século XXI, mergulhados na chamada "globalização" (SANTOS, 2012), sob as consequências do denominado "breve século XX" (HOBSBAWM, 1995). Este século "breve", porém transformador, ensejou um mundo diferente do contexto do século XIX em, pelo menos, três aspectos: 1) deixa de ser eurocêntrico, com o declínio da Europa e a ascensão de outras partes do mundo; 2) "... o globo foi muito mais uma unidade operacional única" (HOBSBAWM, 1995, p. 24), deflagrando o processo de "globalização" a partir de profundas transformações dos meios de comunicação e transporte, e 3) a "... desintegração dos padrões de relacionamento social humano e com a ela a quebra dos elos entre as gerações, quer dizer, entre o passado e o presente" (HOBSBAWM, 1995, p. 24) que ocorreram, principalmente, no capitalismo ocidental, propiciando um individualismo absoluto. Triunfa o indivíduo sobre a sociedade. Rompem-se os fios que conectavam e teciam as relações sociais.

A sociedade moderna ocidental, também chamada por Alain Touraine (2007) de "sociedade dos homens", trouxe a marca de sua criação por um sujeito cujo "... 
polo dominante foi o da conquista, da produção e da guerra, o dos homens, enquanto o polo feminino era a figura principal da inferioridade e da dependência" (TOURAINE, 2007, p. 212).

No entanto, essa mesma sociedade viveu a inversão do modelo clássico de modernidade, tão fortemente polarizado, onde as categorias dominadas - aqui expressa pelas mulheres - transformaram-se em movimentos sociais, cortando seus laços de dependência. Assim, o feminismo nacional e internacional se expressou na construção da organização da sociedade no século $\mathrm{XX}$, abrangendo uma "... trajetória de lutas e resistência das mulheres contra a condição de subalternidade" (CANTO, 2012, p. 39), notoriamente marcando presença na sociedade ocidental.

A partir dos anos 1960 essa realidade ganha notoriedade e há uma ruptura com esse modelo em decorrência do trabalho feminino e da conscientização da mulher. A incorporação maciça da mulher na força de trabalho remunerado abala a legitimidade a que se via o homem como o provedor único da família e apresenta sua competência ao assumir jornadas triplas ou quádruplas diariamente (trabalhadora, mãe, dona de casa, esposa). Além disso, há que se reconhecer também que muitas lutas sociais urbanas foram beneficiárias do movimento feminista como, por exemplo, o movimento sufragista americano (CASTELLS, 1999), o movimento LGBT, dentre outros.

De acordo com Mello (2006), a partir dos anos 1980, as feministas questionaram as estratégias de desenvolvimento e intervenções que não atacavam os fatores estruturais que davam continuidade à opressão e à exploração das mulheres, em especial das mulheres pobres. Não por acaso é notório o aparecimento de organizações de base popular, a maioria criada e dirigida por mulheres, em especial nas áreas metropolitanas de países em desenvolvimento.

É nesse contexto que o movimento feminista passa a utilizar o conceito de "empoderamento"3 (empowerment), sendo nesta mesma década que a palavra "gênero" começou a ser empregada por acadêmicas feministas como categoria

\footnotetext{
${ }^{3}$ O termo "empoderamento" começou a ser usado pelo movimento feminista ainda nos anos 1970 , compreendendo a alteração radical dos processos e estruturas que reduzem a posição de subordinação das mulheres como gênero. As mulheres tornam-se "empoderadas" através da tomada de decisões coletivas e de mudanças individuais.
} 
analítica, visando enfatizar a qualidade fundamentalmente social das distinções baseadas em sexo e corpo por estas serem incapazes de ser historicizadas.

São muitas as mudanças ocorridas nesse período, mas importa-nos destacar a ascensão de uma nova consciência feminina que transforma a vida da mulher. Constrói-se um sujeito político com nova consciência de feminilidade. Surgem as famílias chefiadas por mulheres, mergulhadas no desafio de viabilizar o cuidado da casa, dos filhos, o trabalho, a posição social e os seus direitos enquanto mulheres.

Examinar as tensões, representações e práticas das mulheres em favelas nos traz a afirmação de que esse protagonismo, de fato, vem permeando práticas sociais e políticas. Nesses contextos, o exercício e a consolidação do poder no âmbito local, nos ensina que é necessário examinar como as experiências participativas dessas mulheres, principalmente nas organizações de base comunitária vem se construindo como espaços de luta por políticas públicas que asseguram garantias de direitos em prol da sua cidadania e dos demais moradores.

Baseando-nos nessa premissa, a "feminização do poder" nestes territórios pode ser compreendida como um processo histórico da conquista feminina de acesso às estruturas de poder culturais, sociais, econômicas e políticas (FONSECA; PAGNOCELLI; MAGALHÃES, 2008). Assim sendo, falamos de manifestações diferenciadas do manejo do poder neste contexto de desigualdade e subalternidade, o que implica amplificar nosso olhar sobre práticas locais em um mundo global.

A mulher que nos referimos é aquela que exerce um papel de referência, ou de liderança, nestes territórios, sendo destacada através de uma observação empírica a partir da sua história pessoal de atuação, em geral, através de instituições de base comunitária. Desta maneira, ela não é qualquer mulher da favela e nem de qualquer lugar — ela é ícone da luta cotidiana de um segmento de mulheres da nossa população, que vive em condição de subalternidade por conta de um modelo de desenvolvimento que restringe e cerceia o acesso e a garantia de direitos. Enquadra-se, na maioria das vezes, em preceitos raciais, culturais ou econômicos de subalternização, o que a tem levado a se organizar com o objetivo de revolucionar a materialidade da sua condição de vida. 
Assim, reafirmamos que a mulher de quem estamos falando aqui é um sujeito político que se constrói a cada dia. Ela faz do seu cotidiano uma história de luta e de tomada de consciência permanentes, reinventando uma práxis ${ }^{4}$ política (FONSECA, 2012). Esta mulher traz em si a inquietude de uma revolução silenciosa de comportamentos (DEL PRIORI, 2009), cuja liberdade se anuncia todos os dias.

\subsection{Andanças}

No imaginário social está estabelecida uma relação entre duas cidades distintas: a favela e o asfalto ou, favela e o restante da cidade. A essa primeira, a representação da desordem, do medo, do local de moradia da "classe perigosa" (VALLADARES, 2000) acompanha o imaginário dos habitantes da cidade desde o final do século XIX até os dias de hoje. Ao "asfalto" está associada a imagem do local digno de se viver.

Esse mosaico de desigualdades, expresso na cartografia urbana, revela disputas econômicas, políticas e sociais que fazem parte da história da cidade. A favela, o morro, o território ou a comunidade são espaços populares que ocupam o solo urbano da cidade do Rio de Janeiro que conta histórias de negação, preconceitos e discriminação.

Alguns consensos sobre a favela foram sistematizados por Edmond Preteceille e Licia Valladares (1999): local onde reside a população carente da "cidade maravilhosa"; espaço demarcado não apenas geograficamente, mas que socialmente traz a representação da "cidade ilegal"; um espaço marcado pela irregularidade e ocupação do solo e precariedade de serviços e equipamentos urbanos.

A favela exerce um papel essencial para a cidade: geográfico, econômico, social e político. Ela é parte da cidade, embora historicamente tenha sido recusada sua existência devido a sua imagem negativa, sinônimo de insegurança e violência. Buscando um entendimento nosso do que seja favela, nos valeremos da

\footnotetext{
${ }^{4}$ A filosofia da práxis é, para Gramsci, construção de vontades coletivas correspondentes às necessidades que emergem das forças produtivas objetivadas ou em processo de objetivação, bem como da contradição entre estas forças e o grau de cultura e de civilização expresso pelas relações sociais (GRAMSCI, 1987).
} 
sistematização conceitual realizada por Lícia Valladares (2005) e compartilhada por vários autores (TELLES, 2006; FERNANDES, 2009), que a classifica a partir dos seguintes "dogmas": a especificidade da favela, que the confere um diálogo entre a irregularidade da ocupação do espaço urbano, pobreza e violência com manifestações culturais que constroem marcas de identidade; a favela como o território urbano dos pobres, uma "cidade dentro da cidade", enclave e território da partição, símbolo da segregação sócio-espacial; a unidade da favela no seu sentido de comunidade, onde se evidencia uma realidade plural e multifacetada.

Sob o ponto de vista teórico, não existe uma definição precisa e hegemônica sobre o conceito do que seja favela. A esta se confere múltiplas compreensões e entendimentos que variam de acordo com a concepção de diversos autores, pesquisadores, trabalhadores sociais, organizações públicas, privadas e não governamentais. No entanto, há um argumento que é transversal a todos os significados que esta representação sócio-espacial significa: um lugar das deficiências e carências (SILVA, 2002, 2005) representadas pela falta de saneamento, infraestrutura, pavimentação, legalização fundiária, saúde, dentre outras (FERNANDES, 2012, p. 160).

Uma revisão acerca da construção conceitual do termo realizada por vários pesquisadores e trabalhadores sociais engajados na temática, passou por um processo de construção compartilhada a partir de um seminário promovido pelo Observatório de Favelas, em 2009.

Resultante dessa experiência foram consolidadas as contribuições dos participantes originando na seguinte diretriz que se traduz hoje o que seja favela.

Moradas singulares no conjunto da cidade, compondo o tecido
urbano e integrado a este que não seguem o padrão hegemônico
que o Estado e o mercado definem como sendo o modelo de
ocupação e uso do solo nas cidades. Esses modelos em geral são
referenciados em teorias urbanísticas e pressupostos culturais
vinculados a determinadas classes e grupos sociais hegemônicos
que consagram o que é um ambiente saudável, agradável e
adequado às funções que uma cidade deve exercer no âmbito do
modelo civilizatório em curso (SOUZA, 2009, p. 21). 
Segundo o Censo 2010 (IBGE) o Rio de Janeiro é a cidade no país com a maior população vivendo em aglomerados subnormais ${ }^{5}$, com 1.393 .314 pessoas nas 1071 favelas do Rio, ou seja, 22,03\% dos 6.323 .037 moradores do Município do Rio de Janeiro. E, ainda, que a este número não se somam outros espaços da cidade denominados "conjuntos habitacionais" ou "bairros populares", que possuem características semelhantes às que definem as favelas hoje.

Comparado ao Censo 2000 (IBGE), o crescimento da população em aglomerados subnormais foi de $27,65 \%$, enquanto a cidade regular, excetuando os moradores das favelas, cresceu a um ritmo oito vezes menor, apenas 3,4\%. Estes dados refletem a necessária reflexão sobre esses espaços da cidade que compõem o seu tecido urbano. Olhar para a favela é reconhecê-la nas suas fortalezas e fragilidades, considerando seus desafios, seus contrastes, sua estética, seu modus operandi, capaz de produzir e reproduzir um jeito próprio de dialogar com as demais partes que compõem a cidade, mesmo sendo muitas vezes vista como não desejada a ela.

Falar dos espaços populares no Rio de Janeiro, por vezes revela diferentes expressões e conotações. É muito frequente no contexto desse trabalho, e no exercício profissional dos trabalhadores sociais, do poder público e da inciativa privada, se utilizar o termo "comunidade", uma palavra de uso comum no cotidiano dos moradores das favelas. Assim, para que se possa considerar "favela" ou "comunidade" enquanto categorias estáticas é necessário que se leve em conta a forma como estas são operacionalizadas pelos seus atores sociais.

$\mathrm{O}$ emprego do termo comunidade pode expressar o reconhecimento e valorização do patrimônio material e das relações sociais estabelecidas entre a vizinhança, funcionando como um instrumento simbólico de moralização do espaço de moradia (WEBER, 1999 apud FERNANDES, 2009, p. 377). Portanto, seu uso não necessariamente representa uma aversão ao local de moradia, mas uma forma

\footnotetext{
${ }^{5}$ O IBGE adotou inovações em 2010 para atualizar e aprimorar a identificação dos aglomerados subnormais (assentamentos irregulares conhecidos como favelas, invasões, grotas, baixadas, comunidades, vilas, ressacas, mocambos, palafitas, entre outros). O Manual de Delimitação dos Setores do Censo 2010 classifica como aglomerado subnormal cada conjunto constituído de, no mínimo, 51 unidades habitacionais carentes, em sua maioria, de serviços públicos essenciais, ocupando ou tendo ocupado, até período recente, terreno de propriedade alheia (pública ou particular) e estando dispostas, em geral, de forma desordenada e densa.
} 
de superar o estigma presente no termo "favela", uma vez que este deixou de ser uma indicação de local de moradia e passou a ser uma adjetivação associada à sujeira, desordem, baderna e degradação social (FERNANDES, 2009, p. 377). Nesse sentido, visando amenizar esse estigma, a categoria "comunidade" parece evocar, tanto para os representantes do poder público quanto para os moradores das favelas diretamente envolvidos, uma alternativa simbólica aceitável.

Não obstante o uso disseminado do termo comunidade - em que pese seu caráter político, de reconhecimento da voz e percepção dos moradores sobre seu território -, é importante considerar que as favelas não correspondem a "comunidades" (FERNANDES, 2009, p. 299) como definido anteriormente.

Em uma visão estereotipada, que lamentavelmente permanece, a "favela" é marcada pela demanda de intervenções públicas e seus territórios continuam a ser percebidos como um espaço de ausências - urbanas, sociais, legais e morais (SILVA, 2009).

\begin{abstract}
A valorização de pretensas ausências e de uma aparente homogeneidade, assim como a ênfase na paisagem com elemento definidor daquele tipo de território popular, tem um pressuposto fundamental. Esse, por sua vez, se desdobra em duas formas, pelo menos, de se perceber os moradores das favelas e suas práticas sociais. No caso da premissa, é evidente as referências sociocêntricas que sustentam o olhar dirigido ao espaço favelado. $O$ sociocentrismo se materializa quando, a partir dos padrões de vida, valores e crenças de um determinado grupo social, se estabelece um conjunto de comparações com outros grupos, colocados, em geral, em condições de inferioridade. Os discursos estabelecidos em relação aos espaços populares seguem esse padrão. Eles são definidos por suas ausências, devido ao fato de não serem reconhecidos como espaços legítimos (SILVA, 2002).
\end{abstract}

É nesse lugar que se vive e/ou atuam as lideranças femininas aqui referenciadas. É da favela que esse poder feminino também desponta, num movimento autônomo, individual e que se transforma em ações coletivas e articulações multifacetárias. 


\section{RESULTADOS E DISCUSSÕES}

\subsection{Feminização do Poder nas favelas}

A população que vive nas favelas, território de atuação das lideranças comunitárias, experimenta sistematicamente condições de subalternidade social e econômica determinadas por um conjunto de desigualdades manifestas por sua construção sócio histórica. Políticas assistencialistas, oportunismo político, remoções e resistência marcam períodos que definem a favela enquanto um constructo sóciopolítico repassado por indagações e controvérsias, que hoje está interrelacionado com os demais espaços urbanos em sua permanente luta por reconhecimento social.

Diversos estudos sobre a atuação pública nas favelas cariocas apontam a presença da Igreja Católica a partir da década de 1950. Essa inserção se deu a partir de militantes católicos em busca por soluções para o "problema favela" no Rio de Janeiro nos anos 1950, uma vez que entendiam que as favelas deveriam deixar de ser espaços passivos de intervenções administrativas para se transformar em "comunidades de base" (SOARES; SIMÕES; FREIRE, 2010).

No final dos anos 1970, com o surgimento dos movimentos sociais urbanos, principalmente os vinculados a Igreja Católica através das práticas da Teologia da Libertação e das Comunidades Eclesiais de Base, tiveram um papel importante na formação/capacitação de algumas dessas mulheres.

Os anos 1980 deflagraram um período que podemos chamar de "Era da Participação" (GOHN, 2004). Este foi um período fértil na organização da sociedade civil brasileira, que esteve mobilizada para a conquista de bens e serviços coletivos, contribuindo sobremaneira para a redemocratização do país. Neste contexto, as lideranças femininas começam a ganhar espaço e projeção, consolidando suas lutas e causas sociais permeadas por conteúdos democráticos.

O poder local conquistou maior expressão uma vez que os movimentos políticos passaram a referenciar-se na capacitação técnica das lideranças populares para "... atuar como co-partícipes das políticas públicas locais" (GOHN, 2000, p. 286). Este fato remeteu a um fortalecimento da sociedade civil, que cada vez mais 
se profissionalizava e passava a ganhar um novo formato de organização através do surgimento das Organizações Não-Governamentais ${ }^{6}$ (ONGs).

Estes movimentos ganharam contornos diferenciados nos anos 1990. Ainda que os movimentos sociais estivessem na luta política pela conquista de seus direitos, ocorreu uma mudança de perspectiva que "embora não caminhe no fluxo das grandes mobilizações, continuaram a se ater a grupos específicos, daí a alcunha de grupos de minorias" (GOHN, 2000, p. 322). As ONGs começaram a se organizar e a ganhar força política, muitas vezes tendo em suas práticas contradições explícitas no que se refere a deixar de ser suporte técnico em orientações a lideranças populares para ser intermediárias no repasse de recursos do poder público.

Nesse sentido, a "porta de entrada" para o chamado trabalho comunitário ocorre por motivações diferenciadas. Perpassaram pela educação, pela saúde pública, pela geração de trabalho e renda, pela cultura. No entanto, essas experiências criaram trilhas que se encontram no desejo de transformação individual e coletiva. Com um poder que é político não estatal, as lideranças femininas se apresentam inseridas em organizações sociais de base comunitária comprometida com diferentes causas e frentes de ação.

Muitas mulheres iniciaram a sua luta política e sua construção de liderança local a partir da educação. Mobilizaram-se pelo desejo de mudança de uma das maiores feridas ainda abertas na história do nosso país, na qual a educação constituiu uma poderosa ferramenta de autoritarismo e centralismo, conforme nos ensina o mestre Paulo Freire (1982): “... o centro sabe e fala, a periferia do país escuta e segue" (FREIRE; GUIMARÃES, 1982, p. 42). Associa com muita clareza a educação à emancipação, seja por conhecer os autores e a literatura acadêmica que trata desta associação, seja por conhecer da experiência vivida -individual ou coletivamente- a capacidade transformadora do acesso à informação e ao conhecimento.

\footnotetext{
${ }^{6}$ O termo ONG é uma categoria construída socialmente que vem sendo usado para designar um conjunto de organizações da sociedade civil que se afirma numa identidade comum e na produção de concepções, práticas e instâncias específicas de legitimidade. Suas raízes estão base do movimento popular, muitas vezes associada ao caráter de uma militância política, diante da busca pela conquista dos direitos de cidadania (LANDIM, 1998, p. 24).
} 
Outra dimensão presente na atuação comunitária dessas mulheres se dá na perspectiva da Promoção da Saúde. Esta se sustenta nos preceitos da autonomia, buscando estratégias capazes de alcançar diferentes seguimentos e dimensões que perpassam a produção de melhores condições de vida, considerando as especificidades de cada território com suas variâncias e a capacidade de articular ações locais com políticas públicas.

A violência doméstica também é temática relevante no rol da intervenção dessas mulheres, muito embora seja importante considerarmos que longe de ser um problema localizado em contextos sociais com maior concentração de pobreza a prática sistemática de violência contra a mulher é histórica e permanece viva nas mais diversas culturas.

No enfrentamento das questões supracitadas e em muitas outras aparece à liderança comunitária, articulada politicamente e capaz de representar os interesses da comunidade junto a instâncias específicas do poder público para cobrar efetividade, tangibilidade e transparência, quando o assunto é a oferta de serviços e garantia de direitos para os moradores da favela.

Enquanto membro e representante deste contexto social, essas lideranças estão inseridas em uma variedade de movimentos sociais e em distintos espaços institucionalizados de controle social. Através dessas participações, ela faz circular a sua agenda política, que é construída em uma dimensão coletiva em suas próprias territorialidades, com foco em garantia de direitos. Auxilia-nos nessa análise alguns elementos apresentados por Foucault, Weber e Gramsci.

Buscando compreender como se estabelece a relação de e com o poder das mulheres aqui referenciadas, apoiamo-nos também na compreensão de Michel Foucault (2001), para quem “... o poder não é uma instituição, uma estrutura, uma lei universal: é o nome dado a uma situação estratégica complexa numa sociedade determinada" (FOUCAULT, 2001, p. 89). Para o autor, o poder se expressa através das relações que esse estabelece, não isoladamente, mas com múltiplos focos, com múltiplos sentidos.

As categorias de macro e micropoder abordadas por Foucault permitem-nos analisar o poder como algo que circula, que funciona em cadeia, em rede. $\mathrm{O}$ macropoder (Estado, grandes corporações econômicas, indústria cultural e 
grande mídia) sob o controle da classe dominante, são, assim como o governo representativo, um grande instrumento a reforçar e legitimar o sistema capitalista. Os micropoderes emergem da própria sociedade civil, uma vez que decorre do saber, extraindo-se das práticas sociais e que são forças localizadas que indiretamente reforçam e dão sustentação ao capitalismo.

Essa percepção de Foucault (2001) se dá na medida em que ele compreende a passagem do sistema baseado nos macropoderes sobre a sociedade para o sistema de micropoderes presentes na sociedade como instrumento de luta de minorias, não os pensa como uma via revolucionária, mas como uma forma de se obter conquistas dentro do sistema. Assim, a genealogia do poder corresponde à relação que existe entre conhecimento e poder, informação e domínio sobre o outro (FONSECA; PAGNOCELLI; MAGALHÃES, 2008).

Weber tem a ambição de compreender a sociedade, de fazer uma interpretação, mas não de explica-la totalmente de forma estritamente racional. Sua matriz filosófica e histórica é focada na ação social para interpretar a sociedade, calcada na cultura e na condição humana. Para ele a ação social se orienta pela ação dos outros e daí sua natureza social, porque é relacional.

Por "ação" entende-se, neste caso, um comportamento humano [...] sempre que e na medida em que o agente ou os agentes o relacionem com um sentido subjetivo. Ação "social", por sua vez, significa uma ação que, quanto a seu sentido visado pelo agente ou os agentes, se refere ao comportamento de outro, orientando-se por este em seu curso (Weber, 1999, p. 5).

Mas qual seria o sentido de refletir à luz de Weber sobre a feminização do poder nas favelas do Rio de Janeiro? Consideramos valiosa sua orientação para compreender a sociedade não de maneira totalmente objetiva, mas trazendo os componentes e as implicações sócio-culturais como elementos fundamentais para a sua interpretação.

Acreditamos que as condições sócio-culturais das lideranças e comunidades são fundamentais para entender seu propósito e sua forma de agir, seus avanços e suas dificuldades em termos de ação social. São pessoas que vivem em condições adversas, mas onde há uma cultura de luta por melhorias, de apoio ao próximo, de compartilhar e de acreditar-se em condições de agir socialmente, de interagir, de se 
relacionar. Também há que se enfatizar que estas são, além de mulheres, predominantemente pobres e negras - reunindo assim três formas de discriminação concentradas.

Analisar o quanto as ações dessas mulheres têm se constituído de fato enquanto ação social, cuja atuação individual tem alcance coletivo, se estabelece pelos valores que estas mulheres compartilham. Em relação à articulação política, observamos a ocorrência de diversas atividades nos espaços de discussão com uma crescente participação das mesmas diversas instâncias de luta política. Circulam por muitos espaços diferenciados. Ocupam assentos nos conselhos de direitos, participam de conferências, militam em fóruns da sociedade civil, como os de AIDS e Tuberculose. Atuam em diversos movimentos sociais que lutam por Educação, Saúde, Segurança Pública, Intolerância Religiosa, Diversidade Sexual, Promoção da Igualdade Racial, entre tantos outros.

Nas reflexões de Gramsci destacamos o entendimento de que todos os homens são intelectuais - ainda que não desempenhem socialmente a função de um intelectual - pois todos os homens desenvolvem uma atividade intelectual que contribui para a manutenção ou a transformação de uma determinada visão de mundo (GRAMSCI, 1968, p. 8). Entretanto, ele diferencia os 'intelectuais orgânicos', constituintes de um determinado grupo social, dos 'intelectuais tradicionais' (GRAMSCI, 1968, p.13). Para Gramsci, no entanto, o papel desse intelectual pode ser modificado, através de uma transformação em sua forma de inserção, que passa a ser orgânica em relação a determinado grupo ou classe. Somente assim há a possibilidade da concretização do papel do intelectual enquanto agente transformador.

O autor enfatiza a dimensão de inserção na práxis para o adequado desenvolvimento de pensamentos e ideias, sempre referidos à prática. $\mathrm{O}$ conceito de 'filosofia da práxis' de Gramsci traz ferramentas para se pensar o quanto a prática pode ser transformadora e instrutora: é a partir da vivência, da experiência que transformamos as coisas, nos modificamos, e assim transformamos as relações em nossa volta. Nesse sentido, a prática de que estamos tratando, pode ser potencialmente transformadora de determinadas condições, ainda que singulares e pontuais. 
Fundamentada nessa argumentação podemos compreender esse significado e sentido para essas mulheres de referência em suas favelas. O conhecimento através das questões que se expressam no conjunto da vida social transforma-se em ferramenta política capaz de produzir mudanças. A favela pode ser considerada uma unidade micro ou macro, dependendo da perspectiva que se pretende olhar ou intervir. Mas ela existe e com ela um conjunto de desigualdades expressas na vida social e objetivada no senso comum de como se reconhece que "favela é favela" desde sempre.

A este lugar e suas múltiplas relações constroem-se as redes, que se permeiam das territorialidades e/ou os chamados territórios-redes (BAUMAN, 2005; HAESBAERT, 2002; CASTELLS, 1999). Nessa perspectiva, é um desafio pensar a favela enquanto lócus de convergência e circulação de interesses diversos, permeado por um dispositivo de envolver diferentes segmentos que se conectam.

Esses conceitos se traduzem na prática dessas mulheres, que é territorialmente marcada pela sua história de pertença à favela, mas que se ampliam no ativismo, no compromisso político, no exercício de um trabalho de desenvolvimento comunitário, que se (multi) territorializa por suas falas e ações.

São inquietas e reivindicam para si a condição de sujeito coletivo: são "... atores que partilhem de um conjunto de noções, valores e crenças subjetivas igualmente comuns e que estejam movidos por vontade coletiva" (COUTINHO, 1989, apud YAMAMOTO, 2007, p. 402).

Elas constroem suas trajetórias pautadas pelo inconformismo, alicerçando outros espaços subjetivos e sociais. Fizeram e fazem a diferença nos seus locais de moradia e de trabalho. Percorreram caminhos diversos, transitaram na pobreza. Mas, saem do seu lugar, tornaram protagonistas de histórias pessoais e coletivas de coragem, determinação e enfrentamento.

Entre as passagens adjetas com a vida na favela, suas lutas as transformam numa constelação de experiências, produção de saber, modo de fazer política. Transforma sua ação ou ativismo social numa agenda comungada. Ela é um sujeito político porque, sendo coletivo, sai da esfera privada, da família, da casa para uma atuação ampliada no conjunto das demandas sociais expressas no cotidiano da favela. 
Tem na solidariedade e na luta permanente por justiça social os fundamentos da sua práxis cotidiana - que se estende do sentido mais maternal e fraterno ao enfrentamento da luta política e militância nos movimentos sociais.

Por caminhos diferentes essas mulheres desenvolvem projetos e ações, e pretendem outros que gerem mudanças substantivas, permanentes, que tenham bases transformadoras e gerem mudanças estruturais nas vidas das pessoas. Com qualidade de vida e consciência social as pessoas pleitearão seus direitos, essa é a utopia.

\section{CONSIDERAÇÕES FINAIS OU PARCIAIS}

Com um poder que é político não estatal, as mulheres de referência aqui descritas estão inseridas em organizações sociais de base comunitária e embora distribuídas geograficamente por várias favelas há algo que as une - este "algo" é o desejo permanente e inquieto de mudança, de subversão de uma ordem falaciosa, de transformação de uma realidade injusta.

Elas construíram suas trajetórias pautadas pelo inconformismo, alicerçando outros espaços subjetivos e sociais. Fizeram e fazem a diferença nos seus locais de moradia e de trabalho. Suas falas nos importam particularmente, por falarem de si mesmas, enunciando-se do lócus de suas próprias histórias de vida. Percorreram caminhos diversos, transitaram na pobreza. Mas, saem do seu lugar, tornam-se protagonistas de histórias pessoais e coletivas de coragem, determinação e enfrentamento.

Isto posto, o que desejamos foi aprofundar o entendimento do que chamamos de "feminização do poder" (FONSECA; PAGNOCELLI; MAGALHÃES, 2008) nas favelas. Baseando-nos nessa premissa este processo que vem ocorrendo nestes territórios nos remete a permanente atenção, uma vez que este pode ser compreendido como um processo histórico da conquista feminina. Emergem e “... ocupam um lugar na história” (RICH, 2002 apud RAGO, 2013, p. 313) o que nos remete as provocações de Foucault (1979) quanto a ruptura, como “... entrada em cena das forças (...) o salto pelo qual elas passam dos bastidores para o teatro" (FOUCAULT, 1979, p. 24). 
A participação das mulheres moradoras de favela nessa ação micropolítica de mobilização local e negociação com o poder público desponta com força e coragem numa pluralidade de lutas e conquistas que atravessam o cotidiano marcado por múltiplas violações no que tange a garantia de direitos.

Examinar as tensões, representações e práticas das mulheres nesses contextos de exercício e consolidação do poder no âmbito local nos inspira, bem como examinar experiências participativas das lideranças femininas nas organizações de base comunitária e na construção de espaços de luta por políticas públicas que asseguram garantia de direitos em prol da sua cidadania e dos demais moradores.

Ao referenciarmos a essas mulheres, homologamos falar da mulher negra, predominantemente, como sujeito político tão sinérgico a ela. Mas a questão de classe precisa ser relacionada às condições sociais a que estão submetidas desde sempre as mulheres pobres. Olhar a favela pela perspectiva da mulher, sob o olhar da moradora que atua como gestora/mediadora/liderança comunitária e que é protagonista de uma nova cena política e social faz desse lugar outro lugar.

Estão sempre comprometidas com as lutas comunitárias e populares, inventam e reinventam novas formas de fazer e "resolver a vida"; portanto, transformam o vivido em novas formas de escrever a história - sua e dos outros que as cercam.

Acreditamos que haja uma infinidade delas espalhadas pelas favelas do Rio de Janeiro, do Brasil e do mundo, onde as condições de subalternidade se expressa e onde as políticas públicas estão aquém das demandas do povo. Por essas e outras razões é que podemos afirmar que a "feminização do poder" é, de fato, um movimento que emerge no cenário atual, compreendendo que há um protagonismo da mulher em condições de subalternidade.

\section{REFERÊNCIAS}

AVELAR, Celso. Formação de redes pelas organizações sociais de base comunitária para o desenvolvimento local: um estudo de caso da Cidade de Deus. Dissertação (Mestrado em Engenharia de Produção) - Coppe, Universidade Federal do Rio de Janeiro, Rio de Janeiro, 2008. 
BAUMAN, Zigmunt. Identidade. Rio de Janeiro: Zahar, 2005.

CANTO, Vanessa Santos do. Mulheres negras e relações de poder. In: FONSECA, Denise Pini Rosalem da; LIMA, Tereza Marques de Oliveira (Org). Outras

Mulheres: mulheres negras brasileiras ao final da primeira década do século XXI. Rio de Janeiro: PUC-Rio, 2012.

CASTELLS, Manuel. A sociedade em Rede. Trad. Roneide Venancio Matter. 6.ed. São Paulo: Paz e Terra, 1999.

FERNANDES, Fernando Lannes. Violência, medo e estigma: efeitos sócioespaciais da "atualização" do "mito da marginalidade" no Rio de Janeiro. 2009. 505 f. Tese (Doutorado em Geografia) - Programa de Pós-Graduação em Geografia, Universidade Federal do Rio de Janeiro, Rio de Janeiro, 2009.

. Os jovens da favela: reflexões sobre controle e contenção sócio-espacial dos párias urbanos no Rio de Janeiro. Convergencia. Revista de Ciencias Sociales, San Pedro, v.19. n. 59, p. 159-186, Mayo/Ago. 2012. Disponível em: <http://www.redalyc.org/articulo. oa?id=10521880007> Acesso em: 22 nov. 2014.

FONSECA, Denise Pini Rosalem da; LIMA, Tereza Marques de Oliveira (Org). Outras Mulheres: mulheres negras brasileiras ao final da primeira década do século XXI. Rio de Janeiro: PUC-Rio, 2012.

FONSECA, Denise, PAGNOCELLI, Daniela Santos Machado; MAGALHÃES, Monique Lomeu. Feminização do Poder. Revista Praia Vermelha: estudos de política e teoria social: PPGSS/UFRJ, Rio de Janeiro, v. 18, n. 2, 2008.

FOUCAULT, Michel. Microfísica do Poder. Trad. Roberto Machado. Rio de Janeiro: Edições Graal, 1979.

Graal, 2001. . Tradução de Roberto Machado. 7 ed. Rio de Janeiro: Edições

FREIRE, Paulo; GUIMARÃES, Sérgio. Sobre Educação: diálogos. Rio de Janeiro: Paz e Terra, 1982.

GOHN, Maria da Glória. Teoria dos Movimentos Sociais: Paradigmas clássicos e contemporâneos. 2. ed. São Paulo: Loyola, 2000.

Empoderamento e participação da comunidade em políticas

Sociais. Saúde e Sociedade, v.13, n.2, p.20-31, maio/ago. 2004.

GRAMSCI, Antonio. Os intelectuais e a organização da cultura

Rio de Janeiro, Civilização Brasileira, 1968. 
Concepção dialética da história. Rio de Janeiro: Paz e Terra, 1987.

HAESBAERT, Rogério. Territórios alternativos. Rio de Janeiro: Contexto, ed. UFF, 2002.

HOBSBAWM, Eric. A Era dos Extremos: o breve século XX. Tradução Marcos Santarrita. Revisão técnica Maria Celia Paoli. 2. ed. São Paulo: Companhia das Letras, 1995.

IBGE. Instituto Brasileiro de Geografia e Estatística. Conceitos. Disponível em: <http://www.ibge.gov.br/home/estatistica/populacao/condicaodevida/indicadoresmini mos/conceitos.shtm>. Acesso em: 9 maio 2013.

MELLO, Maria Lucia Vidal. A arte de ser mulher: rupturas com restrições de gênero nas histórias de vida de mulheres. 2006. 381 f. Dissertação (Mestrado em Estudos Interdisciplinares de Psicossociologia das Comunidades e Ecologia Social)-Instituto de Psicologia, UFRJ, Rio de Janeiro, 2006.

PRETECEILLE, Edmond; VALLADARES, Lícia. A desigualdade entre os pobres: favela, favelas. Projeto CNRS/CNPq - Reestruturação Econômica e Social das Grandes Metrópoles e Formação de Políticas Urbanas Modernas e do Projeto Pronex Metrópoles Desigualdades Socioespaciais e Governança Urbana. Ippur/UFRJ, luperj/UCAM, CSU/CNRS, 1999.

RAGO, Margareth. A aventura de contar-se: feminismos, escrita de si e invenções da subjetividade. Campinas: Editora da Unicamp, 2013.

SANTOS, Milton. Por uma outra globalização: do pensamento único à consciência universal. 22 ${ }^{\mathrm{a}}$ ed. Rio de Janeiro: Record, 2012.

SILVA, Jailson Souza. Um espaço em busca de seu lugar: as favelas para além dos estereótipos. [s.I.]: Instituto de Estudos do Trabalho e Sociedade, 2002.

Disponível em:

<http://iets.inf.br/biblioteca/Um_espaco_em_busca_de_seu_lugar.PDF>. Acesso em: 10 maio 2015.

(Org). O que é favela, afinal? Rio de Janeiro: Observatório de Favelas do Rio de Janeiro, 2009.

SOARES, Rafael Gonçalves; SIMÕES, Soraya Silveira; FREIRE, Leticia de Luna. A contribuição da Igreja Católica na transformação da habitação popular em problema público na França e no Brasil. Cuadernos de Antropología Social, n. 31, p. 97-120, 2010. Disponível em <http://www.scielo.org.ar/pdf/cas/n31/n31a05>. Acesso em: 03 jan. 2015.

TOURAINE, Alan. Um novo paradigma: para compreender o mundo de hoje.

Tradução de Gentil Avelino Titton. 3. ed. Petrópolis, RJ: Vozes, 2007. 
TELLES, Vera da Silva; CABANES, Robert. (Org.). Nas tramas da cidade: trajetórias urbanas e seus territórios. São Paulo: Associação Editorial Humanitas, 2006.

VALLADARES, Licia. A Gênese da favela carioca: a produção anterior às Ciências Sociais. Revista Brasileira de Ciências Sociais, São Paulo, v.15, n.44, p. 5-34, 2000.

A invenção da favela: do mito de origem a favela.com. Rio de Janeiro: Editora FGV, 2005.

WEBER, Max. Economia e Sociedade: fundamentos da sociologia compreensiva. Brasília: UNB, 1999.

YAMAMOTO, Marilda Villela. Serviço social em tempo de capital fetiche: capital financeiro, trabalho e questão social. São Paulo, Cortez, 2007.

TORQUATO, Gaudêncio. Comunicação Empresarial/Comunicação Institucional.5. ed.São Paulo: Summus, 1986. 